\title{
Formation of Individual Creative Activity Style of a Prospective Music Teacher
}

\author{
Rezeda C. Khurmatullina ${ }^{1} \&$ Nadezhda P. Yachina ${ }^{1}$ \\ ${ }^{1}$ Kazan (Volga region) Federal University, Kazan, Russia \\ Correspondence: Rezeda C. Khurmatullina, Kazan (Volga region) Federal University, Kremlyovskaya Street 18, \\ Kazan, 420008, Russia. E-mail: rezeda-xurma@yandex.ru
}

Received: January 19, 2014 Accepted: February 22, 2015 Online Published: March 30, 2015

doi:10.5539/res.v7n5p231 URL: http://dx.doi.org/10.5539/res.v7n5p231

\begin{abstract}
The paper presents the analysis of theoretical studies and practical training activities of individual creative activity style of a prospective music teacher. The urgency of this problem is particularly significant in the activities of teachers of artistic and aesthetic cycle (in particular, a music teacher), responsible in many ways for the spiritual, mental, emotional and aesthetic development, the development of creative thinking of students, which is impossible without creative activity of the individual, the need for which is so acute in the era of modern social and economic transformation (Postalyuk, 1993; Berkley, 2004; Jähnichen and Meddegoda, 2014; Jucevičiute-Bartkevičiene, 2011). The paper emphasizes the importance of the educational system, which provides the formation and development of individual creative activity style of a prospective music teacher in educational institution in conditions of university. It is proved that the effective formation of individual creative activity style of a prospective teacher is possible in terms of implementation of educational system based on the unity of the target, managerial, substantive, procedural and personal components of its structure. The contents of the experimental work to verify the effectiveness of the individual creative activity style of a music teacher formation has been disclosed. The results of ascertaining and forming experiments have been analyzed.
\end{abstract}

Keywords: musical and educational activity, musical performance, musical thinking, reflection, musical and pedagogical communication, individual creative style of a musician-teacher

\section{Introduction}

\subsection{Actualizing the Problem}

Development of each person's under education individuality, their positive features and characteristics, promoting their creative self-realization and self-development are the main requirements of modern education. The transition to a multi-level system of higher education, its new international standards necessitate new research problems of formation and development of creative individuality. Self-realization of the creative personality is inextricably linked to his or her individual manner, personal activity style. One of the factors that significantly influence the development of creative activity of the individual is the teacher's work style, which largely affects the form of cooperation with the student, the way to open student's opportunities and abilities, the way to form their cooperation. Pedagogical creativity has interdependent bilateral character. On the one hand, it is the creativity of a teacher, on the other, on the basis of his or her methods, there is a creative activity of students. Only the maximum self-perfection of a teacher's personality makes it possible to activate the power of individual creative development of students. Hence, the teacher's work style is the most significant factor influencing the formation of creatively active personality.

\subsection{Explore Importance of the Problem}

Teacher's attaining of his own style of activity is inextricably linked with the formation of the creative personality as a whole (Ivanenko et al., 2015). The right style meeting the teacher's individuality contributes to the solution of many problems: the effectiveness of pedagogical influence, democratic, emotional harmony in communication between teacher and student, maximum disclosure of individual potential of each student. Hence, it is necessary to establish such a system of a comprehensive training of students and develop such learning technologies that reflect the essence of the professional work of a teacher through their content, forms and methods ensuring the formation of a prospective teacher's own individual creative style of activity. Thus, we are 
not talking about either introduction of some extracurricular activities in the training program, or an increase in students training load, but rather specify the content of the training system components, their combination, their relationship and interaction, as well as of the forms and methods that contribute to the formation of intensive individual creative activity style of a prospective teacher. We believe that in the framework of solving the problem, indicated in this study, the process of creative self-determination of a prospective teacher is activated and intensified, as a solution is designed for a more complete disclosure of individual potential of each student. To date, as well as before, relevant and pressing is a social need for creativity of not only individual educators and innovators, but the entire community of teachers, i.e. each teacher individually. The urgency of this problem is particularly significant in the activities of teachers of artistic and aesthetic cycle (in particular, a music teacher), responsible in many ways for the spiritual, mental, emotional and aesthetic development, the development of creative thinking of students, which is unthinkable without the creative activity of the individual, the need for which is so acute in the era of modern social and economic transformation.

\subsection{Features of Axiological Approach Implementation}

Features of realization of axiological approach in higher education in the context of formation of individual creative activity style of students to be music teachers include the following tasks:

- Study the state of the problem development in domestic and foreign psycho-pedagogical theory and practice;

- Synthesize evidence-based system of intensive formation of individual creative activity style of prospective teachers, in the frames of which;

- To determine the stylistic components of personal and professional qualities and skills important for prospective teachers;

- Define the main individual-oriented methods of work with students, taking into account the peculiarities of their personal qualities and relevant professional skills;

- Identify the pedagogical factors and conditions necessary for the implementation of the pedagogical system of formation of individual creative activity style of prospective teachers;

- Identify the main elements of the content of training in connection with the formation of individual creative activity style of the prospective teacher and the relationship between these elements;

- To conduct a pilot study for testing the model system.

\subsection{Literature Review}

The problem of activity style was taken up by many scholars, both foreign and domestic: Adler (1995), Allport (1961), Merlin (2005), Klimov (1969), Postalyuk (1993) and others. In their study, the problem can be traced in two directions: the style out of subject of activity and style of life, depending on the individual-typological features of a person. In their studies psychologists and educators Andreev (1988), Bogoyavlensky (1972), Zagvyazinsky (1987), Kang-Kalik (1979) and others disclosed the essential features of creativity, its improvisational component, cooperation and emotional immersion in the teaching situation, heuristic search. At the moment, there is a number of studies on the formation of the creative personality of pupils, students and individual style of the teacher Jucevičiute-Bartkevičiene (2011), Jähnichen \& Meddegoda (2014), Berkley (2004), Slosar (1998), Hurmatullina (1996), Safina (2004) and others. The authors of these works consider the versatile possibilities of art, music for the formation of a creative personality.

\section{Materials and Methods}

\subsection{Hypothesis}

The analysis of theoretical studies and practical activity in the aspect of the problem under research has shown that the effective formation of an individual creative activity style of the prospective music teacher is possible, if you implement educational system:

- Based on the unity of the target, managerial, substantive, procedural and personal components of its structure;

- Including the integration of learning content by contacting the overall goal and objectives of the gradual formation of individual creative activity style of the prospective teachers; problems of educational content; organization of students' training and practice with obligatory elements of pedagogical creativity;

- Based on the use of individual-oriented methods of work, involving motivational, informative, procedural, control and evaluation aspects of students and teachers' activities;

- Ensuring the formation of the complex of personal and professionally significant qualities and skills that 
together determine the individual creative activity style of the prospective teacher.

The essence of the system developed by us is presented in Figure 1.

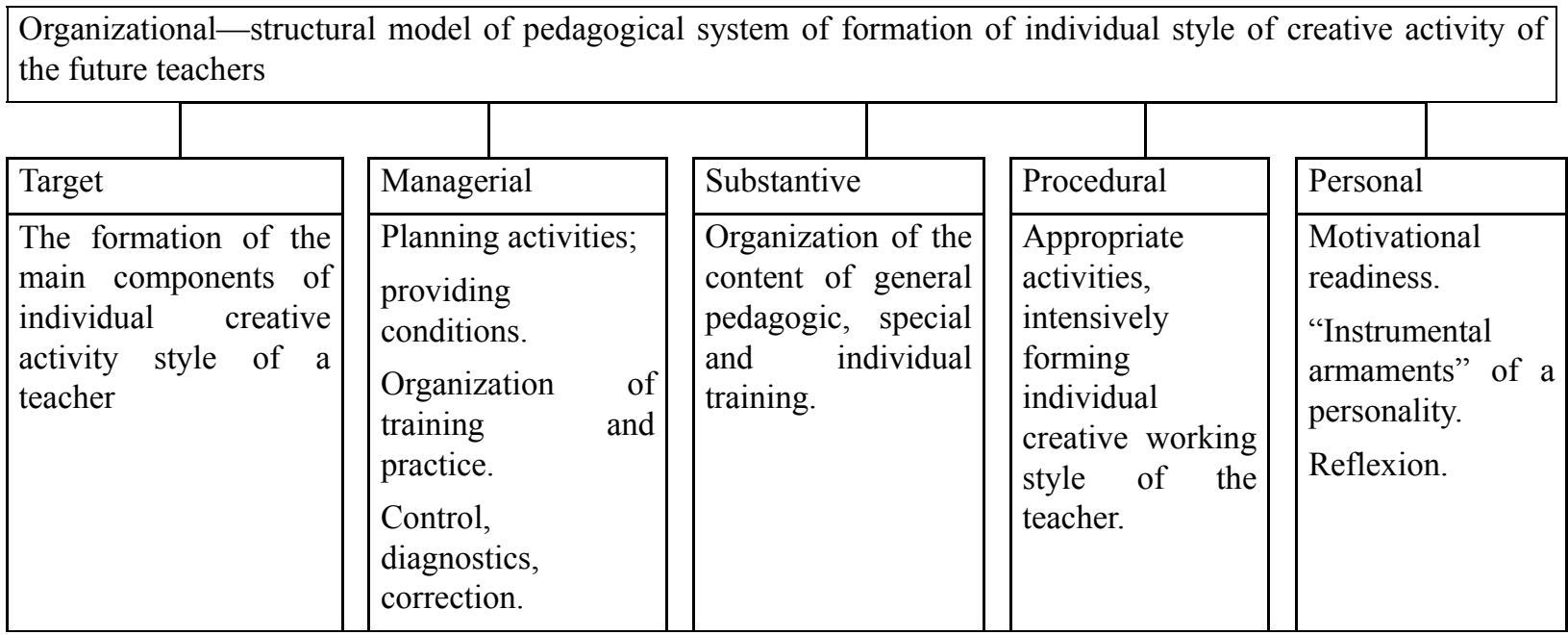

Figure 1. Organizational-Structural model of pedagogical system of formation of individual style of creative activity of the future teachers

The picture shows that the system contains several components.

The first component, a target one, involves the creation of a target unit for the prospective teacher for maximum disclosure of their individual creativity and its manifestation in both educational and cognitive and professional practice.

The managerial component takes upon the very organizational structure of the educational activity and its conditions. Its task is to plan and organize activities necessary for maximum manifestation of creativity.

The aim of a substantive component is in the selection of educational material, forming creative thinking and creative style of activity.

Procedural component includes teaching and practice techniques with the obligatory inclusion of pedagogical creativity elements.

The personal component is shown in the disclosure of individual features, originality of creative expressions of a student, prospective teacher.

\subsection{The Tasks of the Research}

The hypothesis required the following tasks:

- Examine the state of the problem in domestic and foreign psycho-pedagogical theory and practice;

- To develop the evidence - based system for generating individual creative activity style of the prospective teachers;

- Test the effectiveness of the developed system.

\subsection{Theoretical and Empirical Methods}

In our research we have applied the following methods to solve the problem:

- Analysis of psycho-pedagogical and methodological literature on the topic of dissertation research;

- Analysis and synthesis of teaching experience;

- Purposeful pedagogical observation, interviews, questionnaires, testing, interviewing, studying pedagogical documentation;

- Method of modeling, methods of expert assessments and self-evaluation;

- Pedagogical experiment (ascertaining, pilot, formative);

- Methods of mathematical statistics and correlation analysis. 


\subsection{The Trial Infrastructure and Stages of the Research}

The research was done on the basis of arts and pedagogic faculty of the Kazan Academy of Culture and Arts, department of arts of Kazan (Volga) Federal University. At the first stage, the experimental research work, including testing of individual elements of the experimental part of the research was carried out. At the second stage a model of pedagogical system of the individual creative activity style formation of the prospective teacher was developed. We have also elaborated on the system content in relation to the professional work of a music teacher and defined the basic constituent components of individual creative music and teaching activity style, its criteria and methods of diagnostics. At this stage of the research the ascertaining and pilot experiments were held. At the third stage the formative experiment, as well as qualitative analysis and statistical processing of the experimental data, summarizing the results of the research were carried out.

\subsection{Evaluation Criteria}

As the assessment of individual creative activity style of a music teacher the following criteria were suggested:

- Musical performance expression, manifested in the productive use of creative musical and illustrative material and communication of emotional and imaginative content of music;

- Mastery of speech, which is expressed in the absence of monotony, in a passion, artistry, content variability, non-standard presentation of the material;

- Ability to organize musical creativity of students, which is reflected in the nature of asking questions, creating an atmosphere of co-creation and selection of the most effective methods of musical and aesthetic development and education;

- Reflexion, associated with the independent creative goal-setting, the ability to "listen and hear oneself from aside."

\subsection{Experimental Procedure and Its Description}

The experiment has been held for 3 years. Along with the experimental group the control one was identified, which included students with a sufficiently high level of professional training: with secondary special education, i.e., those, who graduated from music schools, music teacher training schools, some of them having practical work experience in school. The experimental group consisted mainly of rural school graduates, some of whom had no musical education even within the children's music school. Thus, the objective training level of students in the control group was higher what put the testing of effectiveness of our model in more stringent conditions.

In the development of individual creative music and teaching activity style five levels have been allocated: from very low (level 1) to a high creative one (5th level).

The level of development was determined, on the one hand, by expert assessment method by teachers of the Music Faculty of all major specialties, on the other hand, by the method of self-assessment, in the course of the so-called credit test in the school curriculum, which is held at the Department of Art in the form of the modeled fragment of a school lesson.

The final examination was assessed by the expert committee consisting of the same members directly in the course of teaching practice at a "control lesson" or preliminary to it lessons.

\section{Results}

The analysis of the results of the control examination at the final stage of the forming experiment showed that the level of development of individual creative musical and educational activity style for all evaluated parameters in the experimental group was higher than in the control one.

At the beginning of the experiment the initial basic components command level of the individual creative style of music and pedagogic activity of students in the control group is higher than that in the experimental group. At the final stage of the forming experiment the students in the experimental group have a higher command level of the given components.

Comparative dynamics factor of students' professional growth in the control group is equal to $8.1 \%$ in the experimental group this factor is $31 \%$.

The final information of the formative experiment on all selected parameters shows significant efficiency of the proposed formation system of the individual creative style of musical and pedagogical activity of the prospective teacher.

To test the significance of the differences Student's criterion was used. The differences appeared accurate at 
0.001 percent level of significance.

In order to determine, which indicator development in the structure of individual creative style of musical and pedagogical activities is aimed to the greatest extent, we developed a specific embodiment of the system model, we used the method of correlation analysis to show the following: at the second examination in the control group as well as at the first examination, the maximum differences between the students were by the 3rd criterion - "the ability to organize musical creativity of students" (P53 = 0.821).

Table 1. The results of the experimental and control groups at the initial and final examination

\begin{tabular}{|c|c|c|c|c|c|c|c|c|}
\hline \multirow{3}{*}{$\begin{array}{l}\text { Number of } \\
\text { the criterion }\end{array}$} & \multicolumn{4}{|c|}{ Experimental group } & \multicolumn{4}{|c|}{ Control group } \\
\hline & \multicolumn{2}{|c|}{ 1st examination } & \multicolumn{2}{|c|}{ 2nd examination } & \multicolumn{2}{|c|}{ 1st examination } & \multicolumn{2}{|c|}{ 2nd examination } \\
\hline & M & & $\mathrm{M}$ & & M & & M & \\
\hline 1 & 2.8 & 0.55 & 4.1 & 0.33 & 3.4 & 0.38 & 4.0 & 0.17 \\
\hline 2 & 3.1 & 0.46 & 4.3 & 0.42 & 3.4 & 0.31 & 3.7 & 0.38 \\
\hline 3 & 3.0 & 0.34 & 4.2 & 0.21 & 3.5 & 0.37 & 3.6 & 0.55 \\
\hline \multirow[t]{2}{*}{4} & 2.6 & 0.39 & 3.8 & 0.35 & 3.2 & 0.24 & 3.6 & 0.23 \\
\hline & 2.9 & 0.40 & 4.2 & 0.23 & 3.4 & 0.18 & 3.7 & 0.20 \\
\hline
\end{tabular}

At the 2nd examination the results of the control group by the level of music performance expressiveness have equaled and became more contrast by the reflexion level (P54=0.539).

In the experimental group at the first examination the maximum differences in the results were in the level of music performance expressiveness and speech skills, at the final stage of the formative experiment the differences by these two criteria decreased $(\mathrm{P} 51=0.695 ;$ P52 $=0.702)$, i.e., the level of the experimental group by these two criteria equaled. In general, all the obtained correlation coefficients between the criteria in the experimental group are higher than in the control group, which allows to conclude that students in the experimental group were became, individual, more interesting in their manifestations of musical and pedagogical creativity.

The general analysis of the results of the first and second examination in the experimental and control groups shows the effectiveness of the proposed system as a whole, which confirms the correctness of our extended at the beginning of the study hypothesis.

\section{Discussions}

The experimental work has confirmed the effectiveness of the proposed educational system. Reliability and validity of the study results were provided by a set of methodological principles of consistency and integrity, versatility of comparative analysis of original sources and monographic studies on the problem of the creative individuality formation of a specialist with a combination of theoretical and experimental methods, the use of a large amount of factual material, a combination of qualitative and quantitative methods, methods of mathematical statistics, as well as the unity of personality and activity approaches at all key stages of the completed research.

The study does not claim to be complete and definitive solution to all the problems associated with the formation of the creative personality of a specialist teacher. The proposed educational system is one of the possible in the future catalogues of technologies of the individual creative activity style formation of a specialist to choose from. Further work in this area could include in particular consideration and inclusion in the educational system of the individual creative activity style formation of the graduate teacher at the adaptive phase of a young teacher; the development of multidisciplinary integral educational technologies of the individual creative style formation of the prospective teacher in connection with regional peculiarities, national cultural and educational environment, and other possible aspects.

\section{Conclusion}

It is noted that every teacher being absolutely independent in creative personality, of course, bears the stamp of university training. That is why, while aiming to nurture individuality, higher school itself must have a unique style, techniques, educational technologies, most fully disclosing individual creativity of each educated. We 
believe that the fundamentals of the creative style of the teacher can and should be laid in the course of vocational training, systematically and constantly introducing students to a state of creative expression, creative discoveries and this valuable state of creative expression of the educational process inevitably transfers in professional practice and becomes a stable characteristic of the individual.

\section{Acknowledgments}

The work is performed according to the Russian Government Program of Competitive Growth of Kazan Federal University.

\section{References}

Adler, A. (1995). Practice and theory of individual psychology: Translated from German. Moscow.

Andreev, V. I. (1988). Basic foundations of creative pedagogy. Kazan: Kazan University Publishing.

Berkley, R. (2004). Teaching to compose as a creative solution to the problem. BJ Music.

Bogoyavlenskaya, D. B. (1972). Psychology of creative abilities. Moscow.

Jähnichen, G., \& Meddegoda, Ch. P. (2014). Metaphoric research of individual creativity teaching in Asia. International journal of human and social sciences, 4(4).

Jucevičiute-Bartkevičiene, V. (2011). The individual vocal expression in future music teacher's personal competence development, Lithuania.Vilniaus pedagoginio universiteto.

Ivanenko, N. A., Burdukovskaya, E. A., Yunusova, A. B., Mukhametshina, R. F., Letyaev, V. A., Islamova, L. R., \& Yeremeyeva, T. S. (2015). Corporativity as a Condition for Developing Teaching Staff. Review of European Studies, 7(4), 49-53. http://dx.doi.org/10.5539/res.v7n4p49

Kan-Kalik, V. A., \& Nikandrov, N. D. (1979). Pedagogic creative activity. Moscow.

Khurmatullina, R. K. (1996). The formation of individual creative activity style of a prospective teacher. Kazan.

Klimov, E. A. (1969). Individual activity style depending on typological properties of a nervous system. Kazan: Kazan University Publishing.

Merlin, V. S. (2005). Personality psychology. Moscow: Moscow psychology and sociology institute publishing.

Olport, G. (1961). Style and personality development. Moscow.

Postalyuk, N. Y. (1993). Didactic system of creative activity style development of students. Kazan.

Safina, L. A. (2004). The formation of creative activity style of a designer in the system of vocational education. Kazan.

Slosar, M .(1998). Elementary school teachers-Criteria, affecting the quality of music education. The Republic of Slovenia.

Zagvyazinsky, V. I. (1987). Pedagogic creative activity of a teacher. Moscow.

\section{Copyrights}

Copyright for this article is retained by the author(s), with first publication rights granted to the journal. This is an open-access article distributed under the terms and conditions of the Creative Commons Attribution license (http://creativecommons.org/licenses/by/3.0/). 